\title{
Self-Medication of Migraine Headaches with Freebase Cocaine
}

\author{
KIRK J. BROWER, MD \\ University of Michigan Medical Center
}

\begin{abstract}
The following report describes a patient who began cocaine use as a self-treatment for migraine headaches and developed a full-blown cocaine dependency disorder. Treatment implications are discussed in relation to the self-medication hypothesis of addictive disorders. The discussion concludes that both initiating and perpetuating factors in substance abuse must be addressed for effective treatment to occur.
\end{abstract}

Keywords-Cocaine, substance abuse, migraines, self-medication.

\section{INTRODUCTION}

COCAINE Is A COMMONLY ABUSED drug with a high potential for adverse consequences (Smith, 1984). Although the etiology of cocaine dependence is complex, the self-medication hypothesis asserts that certain persons initiate cocaine use in order to medicate themselves for an underlying psychiatric disorder (Khantzian, 1985). This hypothesis is supported in part by diagnostic studies which suggest a high prevalence of psychopathology in cocaine abusers (Gawin \& Kleber, 1986; Weiss, Mirin, Michael, \& Sollogub, 1986).

Additional support is provided by a number of case reports which describe patients who apparently used cocaine to self-medicate either affective disorders (Gawin \& Kleber, 1984; Weiss \& Mirin, 1986) or attention deficit disorder (Khantzian, 1983; Khantzian, Gawin, Kleber, \& Riordan, 1984; Weiss, Pope, \& Mirin, 1985). In most of these case reports, specific pharmacotherapy for the psychiatric disorder resulted in dramatic improvement in the cocaine dependence. An unfortunate, albeit presumably unintentional, impression left by some of these reports is that optimal pharmacotherapy for the underlying psychiatric disor-

Requests for reprints should be sent to Kirk J. Brower, University of Michigan Medical Center, UH 8D8806/0116, 1500 E. Medical Center Drive, Ann Arbor, MI 48109-0116.

The author acknowledges the contributions of Drs. Ilse Lowenstam and Jeffrey Cummings. der provides sufficient treatment for the cocaine dependence. Alternatively, Weiss and Mirin (1986) state that pharmacotherapy for coexisting disorders should occur within the context of a comprehensive treatment program for substance dependence.

The following report emphasizes this important point by describing a patient who used cocaine to selfmedicate migraine headaches. Although migraine headaches are not strictly classified as a mental disorder, the case is analogous to the reports cited above in terms of the self-medication motive. Thus, treatment implications are discussed in relation to the selfmedication hypothesis of addictive disorders.

\section{CASE REPORT}

The patient was a 29 year old man who began having headaches at age 23. The headache was described as a throbbing pain over the right temple that lasted between four hours and four days. Headaches were preceded by blurred vision, flashing purple and clear lights, and were associated with nausea. They occurred between one and four times per month. During a headache, the patient preferred to lie still in a dark, quiet room until it subsided. If he took a combination of ergotamine and caffeine early in the course of a headache, he sometimes obtained relief. $\mathrm{He}$ avoided taking more than two pills during an episode and so used the medication suboptimally. Previous trials with propanolol and amitriptyline were unsuccessful in treating his migraines. 
He first tried smoking freebase cocaine at age 27 at the urging of a friend who suggested that it might help a headache he had at the time. Indeed, he noticed immediate and complete relief lasting between five and fifteen minutes, after which the euphoric peak subsided and his headache returned. He found that he could sustain relief with each additional "hit off the pipe" for another five to fifteen minutes, after which the headache returned again. Eventually, he depleted the supply of cocaine, "crashed," and fell asleep. When he awoke, the headache was gone. He repeated this pattern for the next three headaches he had. After his fourth episode of smoking cocaine, he began to use cocaine even when he did not have a headache. The cocaine never brought on a migraine headache if he did not already have one at the beginning of use.

Gradually, his use of cocaine escalated until he was consuming between 10 to 14 grams every two weeks at a cost of $\$ 1000$. Typically, he experienced little or no craving between paydays; but as soon as he had his paycheck in hand, he felt an intense desire to obtain and use cocaine. Within the one month prior to admission, the patient lost his job and marriage due to cocaine use. Having exhausted all social and financial resources, the patient lived on the streets before finally seeking treatment.

The patient did not meet DSM-III-R criteria for abuse of or dependence on any other substances (American Psychiatric Association, 1987), although there was a history of alcohol and marijuana use prior to the initiation of cocaine use.

The patient was treated on a specialized inpatient ward for substance abuse. The treatment consisted of individual and group therapy that was supplemented by drug education. An ergotamine preparation was prescribed for the headaches, and instructions were given for optimal use. During the 28 days of inpatient treatment, the patient remained free of cocaine and experienced only one headache, which was mild and responded to four hours of bedrest. Following the inpatient program, he was discharged to a half-way house for recovering substance abusers.

\section{DISCUSSION}

This may be the first reported case to describe the development of cocaine dependence in a migraine patient. Although abuse and dependence with opioids and barbiturates are well-documented among patients with migraine and other chronic headaches (Langemark \& Olesen, 1984; Medina \& Diamond, 1977), cocaine dependence among these patients is not. More importantly, the case illustrates cocaine use which apparently began as a self-treatment for headaches and culminated in a full-blown cocaine dependence. When planning the treatment strategy for the patient, it was helpful to consider both the factors that initiated cocaine use and the factors that perpetuated addictive use. Therefore, the following discussion will focus on both of these groups of factors and their implications for treatment.

The research regarding risk factors for the initiation of cocaine use has recently been reviewed (Brower \& Anglin, 1987). The major risk factors appear to be male gender, prior use of "gateway" drugs such as marijuana, lack of social connections to family and nonusing peers, other peer influences, and psychopathology. Physical disorders, as exemplified in this case, have not been systematically studied as potential risk factors for initiating cocaine use. Historically, however, cocaine was once considered a panacea for a variety of common ailments such as headaches, the common cold, sore throats, back pain, muscle stiffness, nervous stomach disorders, and asthma (Grinspoon \& Bakalar, 1985). The legal availability and marketing of cocaine in a variety of over-the-counter patent medicines prior to 1914 made the initiation of cocaine use by Americans to self-medicate these ailments inevitable and common.

Although an argument is made that self-medication of headaches was the major factor that initiated this patient's use of cocaine, other risk factors cited above such as male gender, prior use of marijuana, and peer influences were present and operative. It is also possible that the migraine headaches were primarily used by the patient as a rationalization for his initial cocaine use. Likewise, other cocaine addicts, such as the depressed patient described by Weiss and Mirin (1986), may use depression as a rationalization for use. Clinicians need to be careful not to collude with possible rationalizations for cocaine use by neglecting to treat cocaine dependence when present.

An examination of the phenomenology of cocaine dependence suggests that the factors involved in perpetuating addictive use may be quite distinct from those involved in initiating use. The lives of patients dependent on cocaine become increasingly organized around thinking about, obtaining, using, and recovering from the effects of the drug. Their relationship with the chemical eventually supersedes prior relationships with other people and activities. In this patient, for example, compulsive use continued despite adverse consequences such as marital, job, and financial losses. Initially, however, when self-medication was his motive, he was able to terminate his cocaine use when the migraine symptoms subsided. Other patients who are purely self-medicating their psychiatric symptoms should manifest a similar pattern of controlled use. By contrast, his addictive use was related to new symptoms, such as craving, which occurred in the absence of migraines.

Dependent cocaine users often report profound euphoria with immediate use alternating with equally 
profound dysphoria, craving, and other withdrawal symptoms when the acute effects subside (Gawin \& Kleber, 1986). Self-medication of these withdrawal symptoms along with attempts to reexperience the initial euphoria can contribute to compulsive use and a cycle of addiction, regardless of the reasons for initial use. While an increase in the cerebral neurotransmitter dopamine is thought to mediate cocaine's reinforcing and euphoric effects (Wise, 1984), dopaminergic hypofunctioning may underlie the craving and withdrawal symptoms (Dackis \& Gold, 1985a, 1985b). By this conceptualization, the user may be driven to use more cocaine in order to restore dysfunctional dopamine systems.

Further evidence that the risk factors for initial and addictive cocaine use are distinct is provided by longitudinal studies of cocaine users. These studies indicate that not all users of cocaine progress to more frequent or compulsive use (O'Malley, Johnston, \& Bachman, 1985; Siegel, 1984). Although the risk factors for addictive cocaine use are not well studied, genetic factors (Cadoret, Troughton, O'Gorman, \& Heywood, 1986), psychiatric vulnerability (Gawin, 1986), rapid routes of administration such as smoking (Siegel, 1984), and an early age at initial drug use (Robins \& Przybcck, 1985) are likely to be important. A theoretical possibility is that some users are biologically more prone to develop dopamine dysfunction with initial uses and, thus, they proceed to develop an addiction to cocaine.

Treatment in this case consisted of specific pharmacotherapy for the migraines and a conventional, inpatient chemical dependency program with aftercare placement for the cocaine dependence. Specific pharmacotherapy consisted of an ergotamine preparation. Ergotamine, which is believed to exert its therapeutic effect via vasoconstriction, is the pharmacological treatment of choice for acute migraine (Lance, 1986). Similarly, cocaine is a potent vasoconstrictor (Ritchie \& Greene, 1980), and this may have explained its selfmedicating effect in this case. Antidepressants have been used both to prevent migraine headaches (Lance, 1986) and to treat cocaine dependence, even in the absence of coexisting depression (Gawin and Kleber, 1984; Rosecan \& Nunes, 1987). A previous trial of amitriptyline in this patient was ineffective in preventing his headaches. However, antidepressants might represent optimal pharmacotherapy for other patients who suffer with both disorders.

The 28 day period of observation in the protected milieu of a hospital limits the conclusions that can be made about the longterm efficacy of the chosen treatment regimen. Nevertheless, the case illustrates an important treatment principle when chemically-dependent patients present with coexisting disorders and self-medication as a motive. An impression given by other reports which illustrate the self-medication mo- tive is that appropriate clinical treatment of the "primary" disorder, which initiates a patient into abusing cocaine, will result in remission of the cocaine dependence (Khantzian, 1983; Khantzian et al., 1984). In this case, however, migraine therapy in the form of ergotamine would not have been sufficient treatment for the cocaine dependence, because this patient abused cocaine even when his headaches were absent.

When applying the self-medication hypothesis to treatment strategy, it is important to distinguish between initiating and perpetuating factors in substance dependence. Although the self-treatment of headaches was a major factor involved in the initiation of this patient's cocaine use, it was not a particularly important factor in the perpetuation of his compulsive use. As the patient stated, "I knew after four times [of using cocaine to treat my headaches] that I was addicted, because then I began buying cocaine even when I didn't have a headache." Perpetuating factors in this patient's abuse included the powerful, biologically-reinforcing properties of cocaine (Wise, 1984), which were enhanced by the smoking route, and the conditioned cues for craving (Dackis \& Gold, 1985b; Gawin \& Kleber, 1986), such as receiving his paycheck. It is obvious that migraine therapy would not have addressed these perpetuating factors.

In conclusion, the risk factors associated with initial cocaine use and the perpetuating factors that underlie cocaine dependence may be quite distinct. A corollary for treatment is that both initiating and perpetuating factors must be addressed for effective treatment to occur. Patients who start using cocaine or other substances in order to self-medicate their depression, attention deficit disorder, migraines, etc. may develop a substance use disorder that requires its own treatment. Treating substance abuse as secondary to, or as a mere symptom of, an initiating disorder is usually insufficient. This is especially true when powerful, perpetuating factors develop in addition to a pharmacologically-responsive, initiating disorder.

\section{REFERENCES}

American Psychiatric Association. (1987). Diagnostic and statistical manual of mental disorders (Rev. 3rd ed., pp. 165-185). Washington, DC: Author.

Brower, K.J., \& Anglin, M.D. (1987). Adolescent cocaine use: Epidemiology, risk factors, and prevention. Journal of Drug Education, 17, 163-180.

Cadoret, R.J., Troughton, E., O'Gorman, T.W., \& Heywood, E. (1986). An adoption study of genetic and environmental factors in drug abuse. Archives of General Psychiatry, 43, 1131-1136.

Dackis, C.A., \& Gold, M.S. (1985a). New concepts in cocaine addiction: The dopamine depletion hypothesis. Neuroscience and Biobehavioral Reviews, 9, 469-477.

Dackis, C.A., \& Gold, M.S. (1985b). Pharmacological approaches to cocaine addiction. Journal of Substance Abuse Treatment, 2, 139-145.

Gawin, F.H. (1986). New uses of antidepressants in cocaine abuse. Psychosomatics, 27, 24-29. 
Gawin, F.H., \& Kleber, H.D. (1984). Cocaine abuse treatment: Open pilot trial and desipramine and lithium carbonate. Archives of General Psychiatry, 41, 903-909.

Gawin, F.H., \& Kleber, H.D. (1986). Abstinence symptomatology and psychiatric diagnosis in cocaine abusers. Archives of General Psychiatry, 43, 107-113.

Grinspoon, L., \& Bakalar, J.B. (1985). Cocaine: $A$ drug and its social evolution (Rev. ed., pp. 17-44, 154-175). New York: Basic Books.

Khantzian, E.J. (1983). An extreme case of cocaine dependence and marked improvement with methylphenidate treatment. American Journal of Psychiatry, 140, 784-785.

Khantzian, E.J. (1985). The self-medication hypothesis of addictive disorders: Focus on heroin and cocaine dependence. American Journal of Psychiatry, 142, 1259-1264.

Khantzian, E.J., Gawin, F., Kleber, H.D., \& Riordan, C.E. (1984). Methylphenidate (Ritalin ${ }^{\circ}$ ) treatment of cocaine dependenceA preliminary report. Journal of Substance Abuse Treatment, $1,107-112$.

Lance, J.W. (1986). The pharmacotherapy of migraine. Medical Journal of Australia, 144, 85-88.

Langemark, M., \& Olesen, J. (1984). Drug abuse in migraine patients. Pain, 19, 81-86.

Medina, J.L., \& Diamond, S. (1977). Drug dependency in patients with chronic headaches. Headache, 17, 12-14.

O'Malley, P.M., Johnston, L. D., \& Bachman, J.G. (1985). Cocaine use among American adolescents and young adults. $\mathrm{Na}$ tional Institute on Drug Abuse Research Monograph, 61, 5075 .
Ritchie, J.M., \& Greene, N.M. (1980). Local anesthetics. In A.G. Gilman, L.S. Goodman, \& A. Gilman (Eds.), The pharmacologic basis of therapeutics (6th ed., pp. 307-308). New York: Macmillan.

Robins, L.N., \& Przybeck, T.R. (1985). Age of onset of drug use as a factor in drug and other disorders. National Institute on Drug Abuse Research Monograph, 56, 178-192.

Rosecan, J.S., \& Nunes, E.V. (1987). Pharmacological management of cocaine abuse. In H.I. Spitz \& J.S. Rosecan (Eds.), Cocaine abuse: New directions in treatment and research (pp. 255-270). New York: Brunner/Mazel.

Siegel, R.K. (1984). Changing patterns of cocaine use: Longitudinal observations, consequences, and treatment. National Institute on Drug Abuse Research Monograph, 50, 92-110.

Smith, D.E. (1984). Diagnostic, treatment, and aftercare approaches to cocaine abuse. Journal of Substance Abuse Treatment, 1, 5-9.

Weiss, R.D., \& Mirin, S.M. (1986). Subtypes of cocaine abusers. Psychiatric Clinics of North America, 9, 491-501.

Weiss, R.D., Mirin, S.M., Michael, J.L., \& Sollogub, A.C. (1986). Psychopathology in chronic cocaine abusers. American Journal of Drug and Alcohol Abuse, 12, 17-29.

Weiss, R.D., Pope, J.G., \& Mirin, S.M. (1985). Treatment of chronic cocaine abuse and attention deficit disorder, residual type, with magnesium pemoline. Drug and Alcohol Dependence, $15,69-72$.

Wise, R.A. (1984). Neural mechanisms of the reinforcing action of cocaine. National Institute on Drug Abuse Research Monograph, 50, 15-33. 